low frequencies, with some reference to the sources and nature of noise associated with camera-head amplifiers. In this case, the text is rather more mathematical than in the first volume; but a wide variety of circuits is described, including the usse of feedback. Numerical examples are given to illustrate the application to practical equipment.

A somewhat similar presentation is adopted in the third volume, which covers the subject of wave-form generation for television transmission. Separate parts of this book are devoted to the production of waves of sine, rectangular, sawtooth and parabolic form, with details of the various types of valves and circuits suitable for these. The multi-vibrator, in one or other of its different forms, naturally plays a large part in this technique as applied to the reception and analysis of television signals.

The fourth and last volume of this comprehensive work deals with a wide range of circuit techniques, many of which are applicable to the general field of electronics as well as to television engineering. Among the techniques treated are counter circuits, frequency dividers, direct current clamping and restoration, and amplifiers, delay lines and equalizers. Some of these subjects require a mathematical treatment but, in order to facilitate the presentation of the text, many of the mathematical derivations are given in appendixes to the individual chapters.

Altogether these four volumes form a most valuable aid to those engaged in the science and application of the generation and use of television signals, and allied fields of electronics. The texts are very clear throughout and well illustrated by graphs and schematic circuit diagrams. The production of the volumes is of a high standard and is a credit to the publishers as well as to the technical staff of the British Broadcasting Corporation. The work can be confidently recommended as a guide to circuit designers, as a training manual to lecturers and as a general work of reference to the radio and electronies engineer.

R. L. SмIтH-Rose

\section{UNIFICATION OF ANALYTICAL APPROACHES TO ENGINEERING PROBLEMS}

Engineering Systems Analysis

By Prof. Robert L. Sutherland. (Addison-Wesley Series in Instrumentation and Control.) Pp. xii +223 . (Reading, Mass.: Addison-Wesley Publishing Company, Inc.; London: Academic Books, Ltd., 1958.) $60 s$.

THE unification of the analytical approach to engineering problems is an ideal which is sometimes attempted in advanced texts on certain branches of engineering science. It is not, however, very commonly attempted in text-books for undergraduates. Clearly there is a major difficulty in limiting the scope of such a work and in selecting the material to be included. It is, therefore, particularly interesting to find an undergraduate text-book under the title "Engineering Systems Analysis".

The book opens with a study of basic electromechanical analogies and then proceeds to a consideration of mechanical vibrating systems. This is followed by a chapter on oscillations in electrical networks. A section dealing more generally with dynamical systems develops the method of treatment for mixed systems with electrical and mechanical components and explains the use of dimensionless ratios. Dimensional analysis is then treated in considerable detail and its application is illustrated by examples in the field of hydro-dynamics. Thereafter follows a section on the principles of feedback and control and the book concludes with a chapter on analogue and digital computing machines.

With such a wide coverage it might be thought that the treatment would be too superficial to be of real value. In fact the author has succeeded in dealing with a selection of fundamental topics in quite sufficient depth and at the same time in producing a coherent whole. This has in large measure been achieved by the judicious selection of his illustrations.

It would appear from the author's preface that this text-book will meet the needs of certain courses which are being developed in universities in the United States. It is a little difficult to see precisely where this book would fit into the structure of most British undergraduate courses in engineering. None the less, the unification of treatment which is achieved is something of intrinsic value which merits the attention of undergraduates, and the book can certainly be commended as basic reading for both mechanical and electrical engineers. The standard of mathematics involved should be well within the competence of the British undergraduate in his second year.

J. Greig

\section{RUBBER TECHNOLOGY}

Introduction to Rubber Technology

Edited by Maurice Morton. Pp. v +547. (New York: Reinhold Publishing Corporation; London: Chapman and Hall, Ltd., 1959.) 80s. net.

A $\mathrm{N}$ "Introduction to Rubber Technology", edited by Prof. M. Morton, of the Institute of Rubber Research of Akron University, Akron, has first to be compared with the standard work on "Synthetic Rubber" edited by Morton's predecessor, G. S. Whitby. "Synthetic Rubber" is primarily concerned with the preparation and uses of the general purpose styrene-butadiene rubber, with relatively brief mention of chloroprene, nitrile, and butyl rubbers. "Introduction to Rubber Technology" devotes the same fraction of its space to styrene-butadiene rubber as to each of the other rubbers considered. There is no case, therefore, to regard the new book as overlapping seriously the older.

After introductory chapters on the history of rubber technology and polymer chemistry, separate chapters deal with natural rubber, butadiene-styrene, nitrile and acrylate, butyl, polychloroprene, chlorosulphonated polyethylene, polysulphide and silicone rubbers. The various types of rubber additivesplasticizers, antioxidants, and anti-ozonants, accelerators, and fillers-are also treated in separate chapters. Articles on reclaimed rubber, latex and sponge rubber, physical testing, and processing equipment round off a broad survey of modern rubber technology. The only serious omission appears to be of the new polyurethane and polyether foams.

Morton has achieved a large measure of success in welding together the efforts of twenty contributors. The technical level of the articles is uniform and makes for a very readable book. The material is up to date, and presents for the first time in book form much information of value to rubber technologists in 